Brit. Heart F., 1966, 28, 240.

\title{
Q-1 Interval of the Phonocardiogram in Patients with Atrial Septal Defect ${ }^{\star}$
}

\author{
JAMES N. KARNEGIS AND YANG WANG \\ From the Department of Medicine, University of Minnesota Medical School, Minneapolis 14, Minnesota, U.S.A.
}

We have observed that the Q-1 interval of the phonocardiogram may be prolonged in patients with atrial septal defect who are shunting right-to-left, and that the degree of the prolongation appears to vary with the relative size of the right-to-left shunt. It is our purpose to report the correlation of the $Q-1$ interval with the hæmodynamic data in a group of patients with atrial septal defect.

\section{SUBJECTS AND METHODS}

Fourteen patients with atrial septal defect of the secundum variety were studied by phonocardiography and right heart catheterization. Phonocardiograms were obtained using the Sanborn Model 62 TwinBeam Cardiette. Tracings at $75 \mathrm{~mm}$./ $/ \mathrm{sec}$. were recorded at the apical, mid-præcordial, tricuspid, pulmonary, and aortic areas. Logarithmic recordings were made with the diaphragm chestpiece, and stethoscopic recordings with the bell chestpiece. All measurements in this study were made from the apical tracing using the simultaneously recorded lead II of the electrocardiogram as the time reference. All patients had 12lead electrocardiograms. The $P-R$ and $Q R S$ intervals were normal in each.

The Q-1 interval was measured from the beginning of the QRS complex to the onset of the first rapid vibrations of the first heart sound (McKusick, 1958). It is generally agreed that the first component of the first heart sound is coincident with events associated with closure of the mitral valve (Braunwald and Morrow, 1958). The normal Q-1 interval was considered not to exceed $0.074 \mathrm{sec}$. (Craige, 1957).

Hæmodynamic data were obtained from right heart catheterization. Cardiac outputs and shunt flows were determined by the Fick principle. The magnitude of

Received June 14, 1965.

* Supported by U.S. Public Health Service Grants HTS522 (C5) and H-6314 (C1), and the Minnesota Heart Association. the shunts was independently confirmed by multiple Cardio-green indicator dilution curves and modified methyl iodide ${ }^{131}$ inhalation studies (Amplatz et al., 1961). Pressures were recorded with the patient supine using a Statham P23Db strain gauge. One-half of the antero-posterior chest measurement was taken as the zero pressure reference level. In the absence of cardiovascular disease, the left atrial pressure was considered not normally to exceed $13 \mathrm{~mm}$. $\mathrm{Hg}$ (Luisada and Liu, 1956). The mean pulmonary artery "wedge" pressure, which can be considered a measure of the left atrial pressure (Connolly, Kirklin, and Wood, 1954), was equal to the mean right atrial pressure in each patient. An atrial septal defect of sufficient size will cause the pressures in the two atria to be equal (Dexter, 1956).

\section{RESULTS}

The results are summarized in the Table with patients arranged in descending order according to the length of the Q-1 interval. It can be seen that the size of the left-to-right and right-to-left shunts varied widely from patient to patient. The size of the right-to-left shunts was independently estimated by indicator dilution curves obtained by injecting Cardio-green dye into a vena cava and sampling from a peripheral artery. Although Case 3 had a moderately large right-to-left shunt both by blood oxygen saturations and by dye curves, the pulmonary exceeded the systemic blood flow.

The tracings from two patients are presented in Fig. 1. Fig. 1A shows the phonocardiogram of a patient with a large left-to-right shunt of 70 per cent and no detectable right-to-left shunt. The Q-1 interval is a normal one of $0.05 \mathrm{sec}$. The phonocardiogram in Fig. 1B is from a patient with a right-to-left shunt of 42 per cent and a small left-to-right shunt of 14 per cent. The Q-1 interval is prolonged to $0.08 \mathrm{sec}$. 
TABLE

Q-1 INTERVAL IN RELATION TO HEMODYNAMIC DATA

\begin{tabular}{|c|c|c|c|c|c|c|c|c|c|}
\hline \multirow{2}{*}{\multicolumn{3}{|c|}{$\begin{array}{l}\text { Patient, sex, and } \\
\text { age }\end{array}$}} & \multicolumn{2}{|c|}{ Pressure (mm. $\mathbf{H g})$} & \multirow{2}{*}{$\begin{array}{l}\text { Q-1 interval } \\
\text { (sec.) }\end{array}$} & \multirow{2}{*}{ 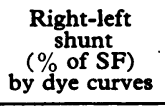 } & \multirow{2}{*}{$\begin{array}{c}\text { Systemic flow } \\
\text { (SF) } \\
\text { (1./min.) } \\
\text { by Fick method }\end{array}$} & \multirow{2}{*}{$\begin{array}{c}\text { Pulmonary flow } \\
\text { (PF) } \\
\text { (1./min.) } \\
\text { by Fick method }\end{array}$} & \multirow{2}{*}{$\begin{array}{l}\text { Ratio } \\
\text { SF/PF }\end{array}$} \\
\hline & & & Mean atrial & Right ventricle & & & & & \\
\hline $\begin{array}{r}1 \\
2 \\
3 \\
4 \\
5 \\
6 \\
6 \\
7 \\
8 \\
9 \\
10 \\
11 \\
12 \\
13 \\
14\end{array}$ & $\begin{array}{l}\mathbf{F} \\
\mathbf{F} \\
\mathbf{F} \\
\mathbf{F} \\
\mathbf{M} \\
\mathbf{F} \\
\mathbf{F} \\
\mathbf{F} \\
\mathbf{F} \\
\mathbf{F} \\
\mathbf{F} \\
\mathbf{M} \\
\mathbf{F} \\
\mathbf{M}\end{array}$ & $\begin{array}{l}55 \\
23 \\
21 \\
27 \\
23 \\
59 \\
49 \\
18 \\
22 \\
24 \\
30 \\
25 \\
17 \\
25\end{array}$ & $\begin{array}{r}14 \\
8 \\
7 \\
9 \\
5 \\
9 \\
10 \\
2 \\
5 \\
3 \\
3 \\
5 \\
5 \\
2\end{array}$ & $\begin{array}{l}100 / 1,18 \\
85 / 0,7 \\
50 / 0,11 \\
94 / 3,6 \\
20 / 0,3 \\
58 /-1,1 \\
60 / 0,9 \\
25 /-2,2 \\
24 / 2,7 \\
27 /-2,2 \\
28 / 0,7 \\
30 / 0,4 \\
23 / 0,6 \\
40 / 0,4\end{array}$ & $\begin{array}{l}0.08 \\
0.08 \\
0.08 \\
0.08 \\
0.07 \\
0.07 \\
0.07 \\
0.06 \\
0.06 \\
0.06 \\
0.06 \\
0.06 \\
0.05 \\
0.04\end{array}$ & $\begin{array}{l}18 \\
11^{\star} \\
22 \\
34 \\
22 \\
+ \\
t \\
0 \\
0 \\
0 \\
0 \\
t \\
0 \\
0\end{array}$ & $\begin{array}{l}5 \cdot 3 \\
6 \cdot 0 \\
7 \cdot 3 \\
6 \cdot 8 \\
4 \cdot 1 \\
7 \cdot 3 \\
2 \cdot 5 \\
4 \cdot 8 \\
3 \cdot 3 \\
5 \cdot 8 \\
5 \cdot 5 \\
9 \cdot 3 \\
6 \cdot 6 \\
3 \cdot 7\end{array}$ & $\begin{array}{r}4.5 \\
4.2 \\
8 \cdot 6 \\
4.9 \\
4.6 \\
11 \cdot 4 \\
7.5 \\
10 \cdot 4 \\
19 \cdot 8 \\
11 \cdot 6 \\
12.8 \\
35 \cdot 4 \\
21.7 \\
10.3\end{array}$ & $\begin{array}{l}1.2 \\
1.4 \\
0.85 \\
1.4 \\
0.89 \\
0.64 \\
0.33 \\
0.46 \\
0.17 \\
0.50 \\
0.43 \\
0.26 \\
0.30 \\
0.36\end{array}$ \\
\hline
\end{tabular}

* With patient breathing 100 per cent oxygen.

t Early break on build-up indicating a just detectable right-to-left shunt.

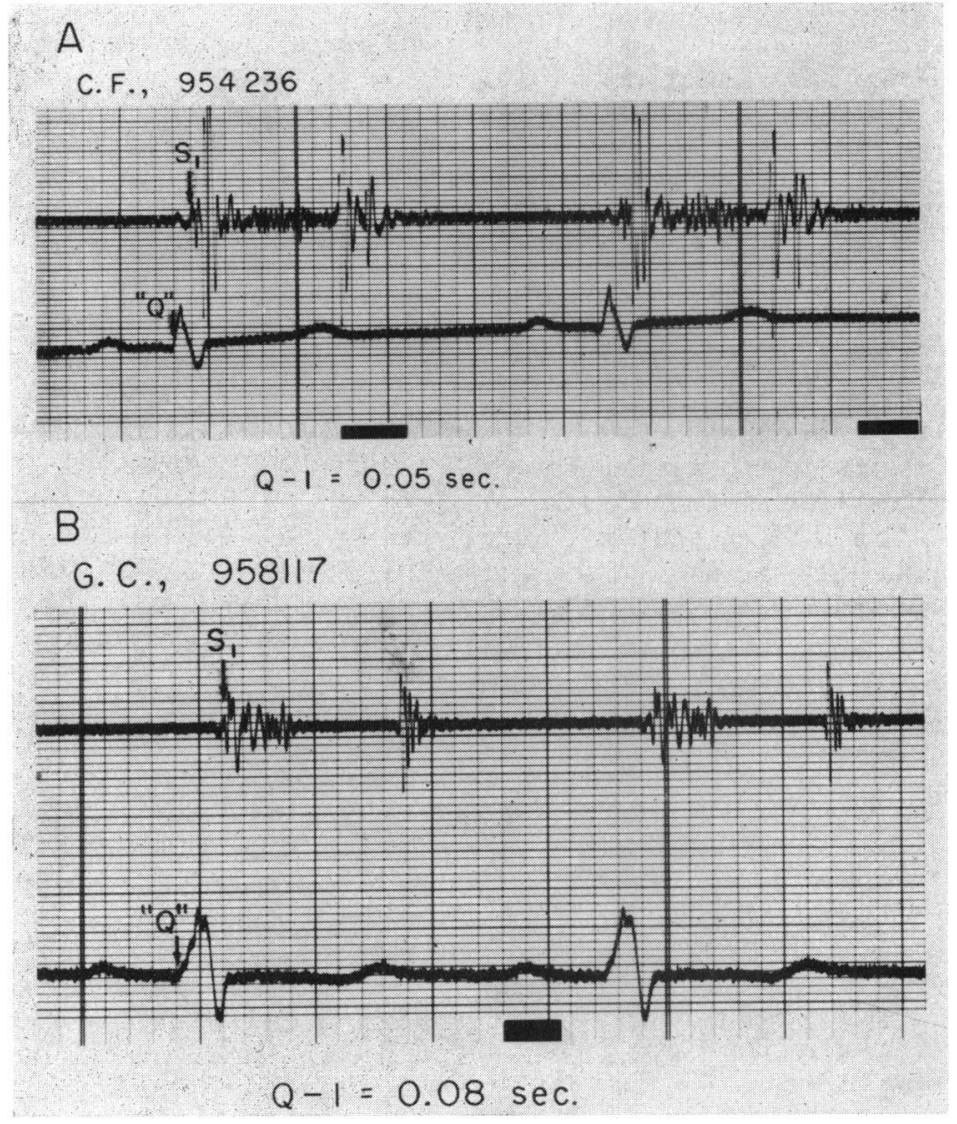

Fig. 1.-The upper tracings of each figure show the phonocardiogram, the lower the simultaneously recorded lead II of the electrocardiogram. (A) (Case 13): Atrial septal defect of the secundum type. There is a large left-to-right shunt of 70 per cent and no detectable right-to-left shunt. The Q-1 interval is a normal one of $0.05 \mathrm{sec}$. (B) (Case 4): Atrial septal defect of the secundum type. There is a right-toleft shunt of 42 per cent and a small left-to-right shunt of 14 per cent. The Q-1 interval is prolonged to $0.08 \mathrm{sec}$. 
Q-1 Interval and Mean Atrial Pressures. The Table shows that the Q-1 interval in patients with atrial septal defect is generally greater in those with the higher mean atrial pressures. The first component of the first heart sound is associated with closure of the left atrio-ventricular valve (Braunwald and Morrow, 1958). The onset of the first heart sound may be delayed in relation to the QRS complex of the simultaneously recorded electrocardiogram when the pressure gradient across the mitral valve is abnormally high, as in mitral stenosis (Wells, 1954). However, in our patients with atrial septal defect the mean atrial pressure did not exceed the normal limits of left atrial pressure, with the exception of Case 1 who was in mild bi-ventricular failure and who had no end-diastolic pressure gradient across the mitral valve. It appears that the prolongation of the Q-1 interval cannot be adequately accounted for by the level of the mean atrial pressures alone.

It can be noted in the Table that the longer Q-1 intervals tend to occur in those patients with the greater right ventricular systolic pressure. Elevation of right ventricular systolic pressure alone cannot explain the prolonged Q-1 interval, however, since patients with a large ventricular septal defect and systemic pressures in the right ventricle may have a normal Q-1 interval (Karnegis and Wang, 1963) if there is no sizeable left-to-right shunt.

It also appears from the Table that those patients with atrial septal defects having the larger left-toright shunts do not show a good correlation between the size of the pulmonary flow and the duration of the Q-1 interval. This could perhaps be due at least in part to the fact that the onset of the first heart sound is associated with events of the left side of the heart (Shah et al., 1963), while the pulmonary flow is more directly associated with events of the right side of the heart. However, it should be noted that the longer Q-1 intervals do occur in the patients with the smaller pulmonary flow. These are the patients who have a sizeable right-to-left shunt.

Q-1 Interval and Systemic Flow/Pulmonary Flow Ratio. In atrial septal defect the right-to-left shunt flow is through the mitral valve instead of the tricuspid valve. Therefore, the ratio of systemic flow to pulmonary flow (SF/PF) can be used as an index of the relative size of the shunt flow across the mitral valve. Table I shows that as the SF/PF ratio increases, in general the duration of the Q-1 interval also increases. Fig. 2, which plots these variables, shows a good positive correlation between the Q-1 interval and the SF/PF ratio.

Comparison of correlation between $Q-1$ interval and relative mitral valve flow in atrial septal defect

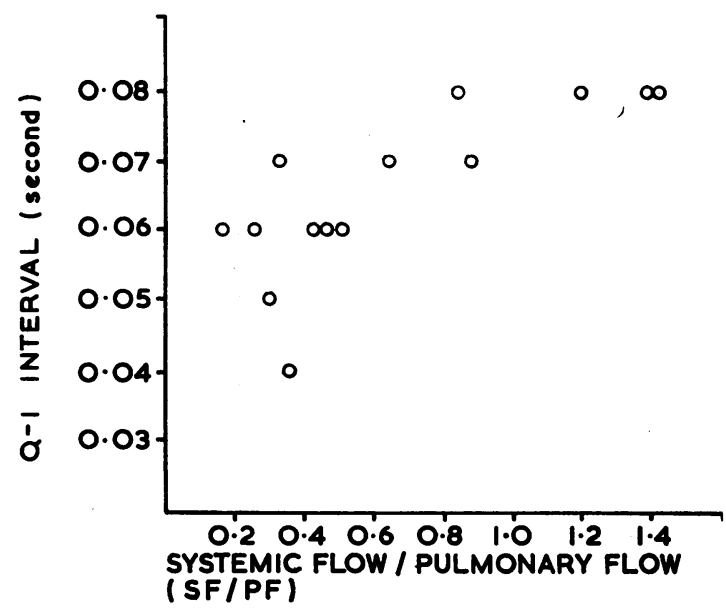

FIg. 2.-Q-1 interval plotted against ratio of systemic flow to pulmonary flow (SF/PF) for patients with atrial septal defect. $\mathrm{SF} / \mathrm{PF}$ is an index of the relative size of the right-to-left shunt. There appears to be a good correlation between the Q-1 interval and SF/PF.

with that in ventricular septal defect, patent ductus arteriosus, and Blalock anastomosis. If the correlation between the Q-1 interval and the relative flow through the mitral valve in patients with atrial septal defect is valid, one would logically expect that a similar correlation would exist for patients with different defects but with similar shunt physiology.

In atrial septal defect the right-to-left shunt flow is across the mitral valve rather than across the tricuspid valve. Therefore, the SF/PF ratio may be taken as an index of the relative size of the shunt. The shunt flow is also across the mitral valve in left-to-right shunting through a ventricular septal defect, patent ductus arteriosus, or Blalock anastomosis. However, in these patients an index of the relative size of the shunt is the ratio of the pulmonary flow to the systemic flow (PF/SF). Thus, the Q-1 interval may be plotted against the SF/PF ratio for the patients with atrial septal defect, and the $\mathrm{PF} / \mathrm{SF}$ ratio for the patients with ventricular septal defect, patent ductus arteriosus, and Blalock anastomosis.

Our previous findings in these conditions (Karnegis and Wang, 1963) are shown in Fig. 3. It appears that the values for atrial septal defect fit well with those for ventricular septal defect, patent ductus arteriosus, and Blalock anastomosis.

\section{Discussion}

Our data indicate that though the Q-1 interval is normal in patients with atrial septal defect and large left-to-right shunt, it may be prolonged in 


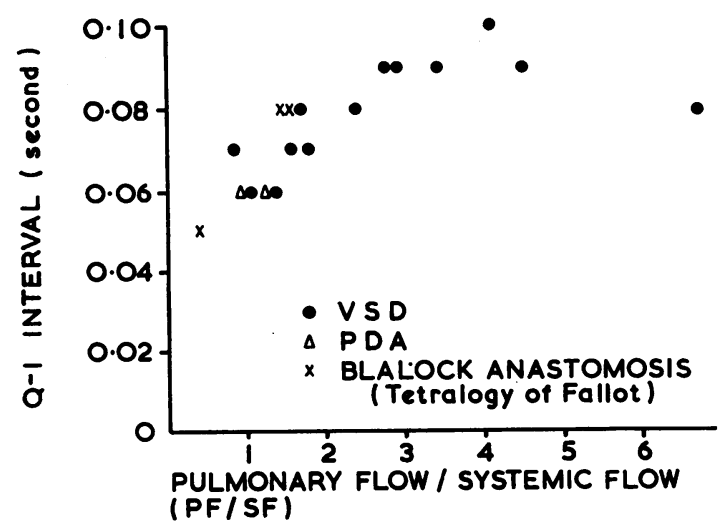

FIG. 3.-Q-1 interval plotted against ratio of pulmonary flow to systemic flow (PF/SF) for patients with ventricular septal defect, patent ductus arteriosus, and Blalock anastomosis. $\mathrm{PF} / \mathrm{SF}$ is an index of the relative size of the left-toright shunt, and shows a good correlation with the Q-1 interval. (From Karnegis and Wang (1963), with the kind permission of the publisher.)

atrial septal defect when there is a sizeable right-toleft shunt. The duration of the Q-1 interval can be related to the flow through the mitral valve. This finding is consistent with that previously reported for ventricular septal defect, patent ductus arteriosus, and Blalock anastomosis, where the shunt flow is also through the mitral valve (Karnegis and Wang, 1963).

The Q-1 interval in our patients with atrial septal defect and right-to-left shunting is at most only moderately prolonged, the longest measuring 0.08 sec. This perhaps reflects the generally smaller size of the right-to-left shunt in patients with atrial septal defect as compared to the left-to-right shunts in ventricular septal defect, patent ductus arteriosus, and Blalock anastomosis.

We can only speculate as to the cause of the prolonged Q-1 interval in these patients. Evidently a raised pressure gradient across the mitral valve is not the explanation, since the mean atrial pressure was only minimally increased in one and normal in the others. It has recently been reported that with ventricular contraction the first component of the first heart sound coincides with the rapid rise of left intraventricular pressure (Shah et al., 1963). In patients with atrial septal defect and right-to-left shunt, if the rate of rise of the left intraventricular pressure were altered in relation to the atrial pressure, the first heart sound could conceivably be delayed and the Q-1 interval prolonged.
A plausible alternative is that the position of the mitral valve at end-diastole may be related to the amount of flow the valve must accommodate (Karnegis and Wang, 1963). Thus, the position of the mitral valve leaflets at the onset of left ventricular systole may be altered by an increased flow through the mitral valve. It would then be possible that the same force produced by ventricular contraction could have different component forces which close the valve. A diminished effective force acting to close the valve could then cause a delay in valve closure and thus a prolonged Q-1 interval.

\section{SUMMARY}

Fourteen patients with atrial septal defect of the secundum type were studied by right heart catheterization and phonocardiography. There appears to be a good correlation between the Q-1 interval and the relative size of the flow through the mitral valve. This finding is consistent with that found in patients with left-to-right shunting through a ventricular septal defect, patent ductus arteriosus, or Blalock anastomosis, conditions in which the shunt flow is also through the mitral valve.

The measurement of the Q-1 interval may be of clinical value in the evaluation of pre-tricuspid right-to-left shunts by phonocardiography.

\section{REFERENCES}

Amplatz, K., Marvin, J., Winchell, P., Gomez, G., Adams, P., and Lester, R. G. (1961). A simple isotope dilution technique for quantitative determination of left to right shunts. Amer. F. Roentgenol., 85, 1053.

Braunwald, E., and Morrow, A. G. (1958). Origin of heart sounds as elucidated by analysis of the sequence of cardiodynamic events. Circulation, 18, 971.

Connolly, D. C., Kirklin, J. W., and Wood, E. H. (1954). Relationship between pulmonary artery wedge pressure and left atrial pressure in man. Circulat. Res., 2, 434.

Craige, E. (1957). Phonocardiographic studies in mitral stenosis. New Engl. F. Med., 257, 650.

Dexter, L. (1956). Atrial septal defect. Brit. Heart f., 18, 209.

Karnegis, J. N., and Wang, Y. (1963). The Q-1 interval of the phonocardiogram in patients with ventricular septal defect, patent ductus arteriosus and Blalock anastomosis. Amer. F. Cardiol., 11, 452.

Luisada, A. A., and Liu, C. K. (1956). Cardiac Pressures and Pulses, p. 26. Grune and Stratton, New York.

McKusick, V. A. (1958). Cardiovascular Sound in Health and Disease, p. 117. Williams and Wilkins, Baltimore.

Shah, P. M., Mori, M., MacCanon, D. M., and Luisada, A. A. (1963). Hemodynamic correlates of the various components of the first heart sound. Circulat. Res., 12, 386.

Wells, B. (1954). The assessment of mitral stenosis by phonocardiography. Brit. Heart f., 16, 261. 